\title{
Diet and Reproductive Function in Wild Female Chimpanzees (Pan Troglodytes Schweinfurthii)at Kibale National Park, Uganda
}

\section{Citation}

Thompson, Melissa Emery, and Richard W. Wrangham. 2008. Diet and reproductive function in wild female chimpanzees (pan troglodytes schweinfurthii) at Kibale National Park, Uganda. American Journal of Physical Anthropology 135(2): 171-181.

\section{Published Version}

doi:10.1002/ajpa.20718

\section{Permanent link}

http://nrs.harvard.edu/urn-3:HUL.InstRepos:3693701

\section{Terms of Use}

This article was downloaded from Harvard University's DASH repository, and is made available under the terms and conditions applicable to Other Posted Material, as set forth at http:// nrs.harvard.edu/urn-3:HUL.InstRepos:dash.current.terms-of-use\#LAA

\section{Share Your Story}

The Harvard community has made this article openly available.

Please share how this access benefits you. Submit a story.

\section{Accessibility}




\title{
Diet and Reproductive Function in Wild Female Chimpanzees (Pan troglodytes schweinfurthii) at Kibale National Park, Uganda
}

\author{
Melissa Emery Thompson* and Richard W. Wrangham \\ Department of Anthropology, Harvard University, Cambridge, MA 02138
}

KEY WORDS ovarian function; sexual swellings; estrogens; endocrinology; conception; energy balance; feeding behavior

\begin{abstract}
Human female reproductive function is highly sensitive to current energetic condition, indicating adaptation to modulate reproductive effort in accordance with changing ecological conditions that might favor or disfavor the production of offspring. Here, we test the hypothesis that reproductive capacity in female chimpanzees is likewise limited by current energetic condition. We used 12 years of data on wild chimpanzees (Pan troglodytes schweinfurthii) in the Kanyawara community of Kibale National Park, Uganda, to examine the relationship of dietary quality, as assessed by fruit components of the diet, to the occurrence of sexually receptive females, concentrations of ovarian steroid hormones, and timing of conception. We found that the frequency of
\end{abstract}

The availability of energy is a key limiter to reproduction in female mammals (Gadgil and Bossert, 1970; Trivers, 1972; Schneider and Wade, 2000). However, there are many different adaptive strategies for meeting the energetic demands of reproduction (Drent and Daan, 1980; Boyd, 2000; Lewis and Kappeler, 2005). Chimpanzees pursue high-quality, unpredictable resources (Goodall, 1986; Wrangham et al., 1996), making it a particular challenge to meet the energetic demands necessary to successfully carry out a long and costly reproductive effort.

Variation in reproductive performance has been documented in wild chimpanzees among populations, among years within the same population, and among individuals (Gombe, Tanzania: Pusey et al., 1997; Wallis, 1997; Kanyawara, Uganda: Emery Thompson et al., 2007; across populations: Knott, 2001; Brewer-Marsden et al., 2006). The reasons are not well understood, but preliminary evidence suggests that relatively minor improvements in food supply might promote an increase in conception probability. Thus in Gombe, conceptions have shown seasonal peaks when feeding parties are largest (Wallis, 1997), which generally occurs when there is increased food availability (Chapman et al., 1994; Wrangham, 2000; Mitani et al., 2002). Furthermore dominant female chimpanzees had higher birth rates, increased infant survival, and faster maturing daughters, possibly due to nutritional differences (Pusey et al., 1997). In Taï, Ivory Coast, the number of females in estrus was correlated with food abundance (Anderson et al., 2006). Finally in Kanyawara, females that occupied core areas of relatively high food availability had shorter birth intervals, higher ovarian hormone levels, and higher infant survivorship than others (Emery Thompson et al., 2007). Conception data from Hanuman langurs females having sexual swellings was positively related to the consumption of drupe fruits. Estrogen levels of both cycling and noncycling females increased during seasonal peaks in the consumption of drupe fruits. When average fruit consumption remained high across months, females conceived more quickly. These results support the hypothesis that cycling and conception in chimpanzees are contingent upon high energy balance, and they indicate that the availability of fruit is a key variable limiting reproductive performance in chimpanzees. Chimpanzees appear to share with humans a reproductive system that is primed to respond to proximate levels of energy acquisition. Am J Phys Anthropol 135:171181, 2008. ๑2007 Wiley-Liss, Inc.

(Presbytis entellus: Koenig et al., 1997), long-tailed macaques (Macaca fascicularis: van Noordwijk and van Schaik, 1999), and orangutans (Pongo pygmaeus: Knott, 1999 ) indicate a similar sensitivity to seasonal changes in food abundance.

These findings suggest that females might become more likely to conceive as a result of a seasonal increase in food availability. Such a pattern would conform to the reproductive system of humans, in which the probability of conception is controlled by varying ovarian hormone production in relation to energetic condition (Ellison, 1990, 2003; Ellison et al., 1993). This hypothesized sensitivity of conceptions to food abundance would contrast, however, with the system found in some smaller primates in which births, rather than conceptions, tend to occur during periods of high food availability (Lindburg, 1987).

In this article, we test the hypothesis that reproductive function is positively correlated with dietary quality. We do so by examining dietary composition in relation to

Grant sponsor: National Science Foundation; Grant numbers: 0416125, 0416126; Grant sponsors: Leakey Foundation, Wenner-Gren Foundation, Harvard University, National Institutes of Health.

*Correspondence to: Melissa Emery Thompson, Department of Anthropology, Harvard University, 11 Divinity Avenue, Cambridge, MA 02138. E-mail: memery@fas.harvard.edu

Received 8 September 2006; accepted 17 August 2007

DOI 10.1002/ajpa.20718

Published online 28 November 2007 in Wiley InterScience (www.interscience.wiley.com). 
TABLE 1. Kanyawara study subjects

\begin{tabular}{|c|c|c|c|c|c|}
\hline ID & Birth year $^{a}$ & Observation years $^{\mathrm{b}}$ & Mean observation hours/year & Parity $^{\mathrm{c}}$ & Urine samples ${ }^{\mathrm{d}}$ \\
\hline $\mathrm{AT}$ & 1982 & $1994-2004$ & 610 & Primi 1997 & 104 \\
\hline $\mathrm{AR}$ & 1943 & $1993-2004$ & 309 & Multi & 47 \\
\hline $\mathrm{AS}$ & 1990 & 2001-2002 & 367 & Nulli & 8 \\
\hline BL & 1960 & 2000-2004 & 593 & Multi & 34 \\
\hline FG & 1955 & 1993-1998 & 407 & Multi & 14 \\
\hline $\mathrm{KL}$ & 1970 & $1993-2000$ & 406 & Multi & 53 \\
\hline LP & 1955 & $1993-2004$ & 636 & Multi & 185 \\
\hline LR & 1989 & $2000-2004$ & 918 & Primi 2003 & 138 \\
\hline $\mathrm{NE}$ & 1983 & 1997-1998 & 587 & Nulli & $\mathrm{n} / \mathrm{a}$ \\
\hline NL & 1982 & $1997-2004$ & 722 & $\begin{array}{l}\text { Primi } 2000 \\
\text { Multi } 2004\end{array}$ & 140 \\
\hline OU & 1979 & $1993-2004$ & 774 & $\begin{array}{l}\text { Primi } 1994 \\
\text { Multi } 1998\end{array}$ & 206 \\
\hline TG & 1980 & 1993-2004 & 641 & $\begin{array}{l}\text { Primi } 1995 \\
\text { Multi } 2000\end{array}$ & 129 \\
\hline
\end{tabular}

${ }^{\text {a }}$ Due to female dispersal in chimpanzees, most birth years are estimates.

${ }^{\mathrm{b}}$ Years of observation when sexually mature (after swelling cycles begin) and member of central female neighborhood.

${ }^{\mathrm{c}}$ Indicates whether females was observed while nulliparous, primiparous, or multiparous; dates are indicated if females switch categories during study.

${ }^{\mathrm{d}}$ Urine sampling was conducted from Dec $1997 \mathrm{Feb} 2004, N$ excludes samples while pregnant.

the frequency of sexual swellings, the levels of urinary estrogens and progestins, the timing of conceptions and births, and the waiting time to conception. We specifically test the relationship of these reproductive variables to the predominance of ripe fruit in the diet. In addition, we evaluate whether certain subsets of fruits-those preferred in the diet of these chimpanzees-exert a particular influence on reproductive events. Our analysis uses 12 years of dietary and reproductive data from the Kanyawara community of chimpanzees in the Kibale National Park, Uganda, including 6 years of hormonal assays.

The diet of this population is dominated by ripe fruit produced by less than 20 tree species in fruiting seasons lasting at most a few weeks annually for each species (Wrangham et al., 1996, 1998; Wrangham, 1997; Conklin-Brittain et al., 1998). Fruiting seasons are unpredictable in their timing, duration, and productivity. They therefore offer extensive opportunities for testing the hypothesis that the probability of conception is correlated with the food supply.

\section{METHODS Study site}

We studied the habituated chimpanzee community in the Kanyawara region of Kibale National Park, Uganda. The Kanyawara home range comprises approximately $35 \mathrm{~km}^{2}$ (Wilson, 2001) of predominantly $(60 \%)$ moist deciduous forest, with small areas of swamp, grassland, and colonizing forest (Chapman and Wrangham, 1993). Kanyawara chimpanzees have never been directly provisioned, though proximity to human villages leads to some crop-raiding (primarily banana stems).

Systematic data collection on the Kanyawara community has been continuous since 1988. This study incorporates results from over 22,500 observation hours from January 1993 to December 2004. The community consisted of 36 chimpanzees at the beginning of the study and 42 individuals (including 10 adult males and 21 subadult and adult females) at the end of the study. Observations were made daily by a team of two or more permanent Kibale Chimpanzee Project field staff (FAs), normally accompanied by one or more student researchers. FAs recorded scan samples every 15 min during nest-to- nest party follows, including the following: (a) location of chimpanzees on a trail map, (b) party composition, and (c) food species and part(s) being consumed. Sexual swelling development (none, partial, or maximal) was recorded on each independent observation of a female; in the event that swelling size fluctuated during a single day, the maximum swelling level was recorded for that day.

To control for probable individual differences in diet resulting from habitat variation we analyzed data only for feeding groups containing one or more of the 12 females who were recorded in more than $15 \%$ of scan samples and whose core areas are in the central region of the home range (Table 1, Emery Thompson and Wrangham, 2006; Emery Thompson et al., 2006). They differ from other females in their hormonal function and reproductive parameters (Emery Thompson et al., 2007). In contrast to peripheral (northern) females, these central females occupy ranges within a relatively food-rich area of the home range, and their ranges overlap considerably among one another and with the area used most intensely by males for foraging (Emery Thompson et al., 2007). These findings suggest that these females have access to the same feeding areas, and that feeding data collected on chimpanzee parties can be expected to be broadly representative of the diets of these central females (though perhaps not other females in the community).

\section{Diet}

Extensive studies of the feeding behavior of Kanyawara chimpanzees, including nutritional analyses of many foods, have previously been published (Wrangham et al., 1991, 1998; Conklin-Brittain et al., 1998, 2006). On the basis of these previous studies we defined two broad measures of dietary quality that we predicted would positively influence chimpanzee reproduction:

Ripe fruit consumption. Ripe fruit pulp constitutes the dominant food type for this species (Hladik, 1977; Wrangham, 1977; Isabirye-Basuta, 1989; Yamagiwa et al., 1996; Conklin-Brittain et al., 1998; Newton-Fisher, 1999; Furuichi et al., 2001) so much so that the abundance of trees producing large, fleshy fruits can be used to predict relative chimpanzee densities (Balcomb et al., 
2000). Therefore, we calculated the percentage of ripe fruit in the monthly diet as one indicator of relative dietary quality (n.b., all references in the text to fruit refer to ripe fruit pulp). The proportion of fruit in the chimpanzee diet at Kanyawara is significantly correlated with fruit availability calculated from phenological transects (Wrangham et al., 1991, 1996; Sherry, 2002).

Preferred fruit consumption. In a naturalistic setting, "preferred" foods are defined as those selected disproportionately often relative to their abundance within the population's habitat, and these are presumed to be of relatively high value to the animal (Leighton, 1993; Marshall and Wrangham, in press). In practice, this means that the consumption of preferred foods is strongly correlated with seasonal availability. At Kanyawara, approximately half of the fruit component of the chimpanzee diet is comprised of drupe fruits which are available in short, sporadic seasons and whose consumption is significantly correlated with availability (Wrangham et al., 1996). The remaining half consists of various fig species, which are available in nearly all months of the year, yet are eaten in inverse proportion to drupe fruits (Wrangham et al., 1996; Sherry, 2002). In other words, figs are used extensively by Kanyawara chimpanzees, but primarily when key drupe fruit species are not available. Thus, we examined the proportion of ripe drupe fruits in the diet to estimate preferred fruit consumption.

We collected feeding data from parties containing at least one of the central females whose reproductive data were being studied. Diet was calculated on a monthly basis as the number of scans in which each plant species/part was consumed as a proportion of all feeding scans, and analyses were limited to months with greater than $50 \mathrm{~h}$ of observation time $(N=128)$. In other studies of wild chimpanzees, fruit consumption calculated in this manner produces estimates comparable to data taken from 15-min point scans of individual focal animals (Emery Thompson, 2005a). In monthly diets we calculated: (a) the percentage of ripe fruit; (b) the percentage of ripe drupe fruit; and (c) whether the month occurred in a fruiting "season" (i.e., when a single fruit species comprised $\geq 40$ percent of the diet).

Visibility conditions limit our ability to record the feeding behavior of all individuals in a chimpanzee party, thus dietary data were analyzed as the food item being eaten by the majority of individuals in the party. Observers record any other items they see being consumed by party members, but multiple items were consumed in less than 1 percent of feeding observations (519/57799) at Kanyawara between 1993 and 2004. We note an exception for THV (terrestrial herbaceous vegetation) feeding, in which animals may consume a mixture of species or of THV piths and leaves; note that these observations are designated generally as THV eating. Also, many trees contain a mixture of ripe and unripe fruits, and we expect that there may be some variability in the type of fruits consumed within and between feeding sites. Unless this distinction is very clear, these feeding events are recorded as ripe-fruit eating if the tree contains mostly ripe fruits and/or individuals can be clearly observed selecting ripe fruits.

\section{Ovarian hormone analysis}

From December 1997 to February 2004, Kibale field staff collected urine samples as frequently as possible by pipetting from vegetation or from plastic sheets placed under the subjects (Knott, 1997). Samples were stored in leak-proof tubes, labeled with date, time, and identity of subject, and frozen the same day at $-20^{\circ} \mathrm{C}$ (Kesner et al., 1995). They were later transported on ice to the Primate Reproductive Ecology Laboratory at Harvard University. We conducted enzyme immunoassay for estrone conjugates $\left(\mathrm{E}_{1} \mathrm{C}\right)$ and pregnanediol-3-glucuronide $(\mathrm{PdG})$, metabolites of estrogen and progesterone, respectively, with reagents provided by the Clinical Endocrinology Laboratory at University of California, Davis (R522 anti-E ${ }_{1} \mathrm{G}$ and 13904 anti-PdG: C.J. Munro). Assay procedures and validations followed existing protocols (Czekala et al., 1986; Shideler et al., 1990; particulars on our laboratory's $\mathrm{E}_{1} \mathrm{C}$ and PdG assays are provided elsewhere (Emery Thompson, 2005b). All urinary hormone measures were standardized to creatinine $(\mathrm{Cr})$ to control for concentration (Taussky, 1954). Samples with very low creatinine levels $(<0.08)$ were discarded.

We used reproductive records to assign each urine sample to the reproductive state of the subject. We diagnosed pregnancy by a steep, sustained increase in ovarian hormone levels (Emery Thompson, 2005b) and confirmed this with hCG test strips (Aimstick, Craig Medical, Vista, CA). Samples from pregnant females and adolescents were excluded from endocrine analysis, while the remaining samples were classified into three categories: noncycling, cycling-baseline, and cyclingpeak. Noncycling samples were collected from females during the period from birth of their infant to the first post-partum maximal swelling. Cycling-baseline samples were collected from females who had initiated cycling but were currently nontumescent, excluding the 10 days following maximal swelling detumescence to exclude luteal hormone fluctuations. Finally, cycling-peak samples were collected from females during the period of maximal sexual swelling, defined by tumescence of circumanal and vaginal tissues and closure of the labia to form a tight slit (Dahl et al., 1991).

We calculated a monthly average $\mathrm{E}_{1} \mathrm{C}$ and $\mathrm{PdG}$ for each female in each reproductive state and log-transformed the data prior to statistical analysis. We next calculated a monthly grand mean for all females, considering each reproductive state separately. To examine the effect of fruiting seasons (see previous section) on hormonal levels, we used a paired $t$-test to compare the mean hormonal indices during each drupe fruiting season with the month that immediately preceded the season; we then compared hormonal levels in each drupe season with those in the month immediately following. Sample sizes vary because of sampling success and availability of females in each reproductive state. We present data for $\mathrm{E}_{1} \mathrm{C}$ in all three reproductive categories. Since progesterone shows little activity during sexual swelling (Graham et al., 1977; McArthur et al., 1981), PdG was only analyzed for noncycling and cycling-baseline samples.

\section{Other reproductive variables}

We investigated the relationship of diet to four reproductive events: occurrence of sexual swelling, timing of conception, timing of birth, and waiting time to conception. Frequency of sexual swelling was measured as the percentage of the observed potentially reproductive females exhibiting a maximal sexual swelling in each study month. We used Spearman's correlations to test the prediction that sexual swellings were more frequent in months of high dietary quality. Pregnant females and 
females in their first 6-months of lactation were not considered potentially reproductive. Note that three females in this community have been observed with sexual swellings between 6 and 12 months after birth with the previous offspring still surviving; cycling resumption during the first year of lactation has also been observed at Mahale (Takasaki et al., 1986) and at Taï (Boesch and Boesch-Achermann, 2000).

We identified a conception window for 19 infants born between 1993 and 2005 whose date of birth was known within 1 month (Table 2). We began by back-calculating 230 days from the estimated birth date of the infant according to observed gestation lengths for captive (range $=202-261$ days, $n=56$ : Yerkes, 1943; Martin et al., 1978; Shimizu et al., 2003) and wild chimpanzees (range $=207-259, n=42$ : Wallis, 1997; Emery Thompson, unpublished data). Eleven of these conceptions were confirmed by a urine sample taken in the first trimester of pregnancy. For 18 conceptions, we could derive a separate estimate based on the last mating day or the last day of maximal swelling prior to hormonal confirmation of pregnancy. All estimates derived from estrous dating were within 30 days of the estimates produced by backdating 230 days from birth. We used Mann-Whitney $U$ tests to compare dietary quality in months in which one or more conceptions occurred versus months in which no conceptions occurred. Simiarly, we compared months in which one or more births occurred to those in which no births occurred.

We defined waiting time to conception as the period from the first month in which a postpartum maximal sexual swelling was observed up to, and including, the month of conception. For each conception, we calculated the mean ripe fruit and ripe drupe fruit consumption by chimpanzees over the entire waiting time to conception. We then used regression and partial correlation (correcting for female identity) to test the prediction that increased dietary quality led to shorter waiting time to conception. The mean percentage of ripe fruit in a randomly selected sample of months reaches an asymptote after approximately 20 months. Therefore, for one female who conceived after an unusually long cycling period of 40 months, we considered only the last 20 months prior to conception. Results are not qualitatively affected if this female is excluded. There were 12 conceptions for which we had data on the time of cycling start and conception. All statistical analyses were performed with SPSS 14.0 (Chicago, IL).

\section{RESULTS \\ Dietary analyses}

Chimpanzee diet during the years 1993-2004 conformed to earlier patterns reported for Kanyawara. Ripe fruit constituted 68.1 (range: 9.7-96.1) percent of the chimpanzees' average feeding time per month. The seven most frequently consumed fruits, according to average $\%$ of the chimpanzee diet across all months, were the same as those identified in a previous study (Table 3) and accounted for just over half $(56.2 \%)$ of the chimpanzees' feeding time and $82.5 \%$ of all fruit feeding time. Two additional drupe fruits, Linociera johnstonii and Teclea nobilis comprised only 1-2\% of the chimpanzee diet on average, but were used intensely during a small number of months. Three fig species (Ficus natalensis, F. sansibarica, and $F$. exasperata) were consumed in the majority of study months, indicating that they were broadly

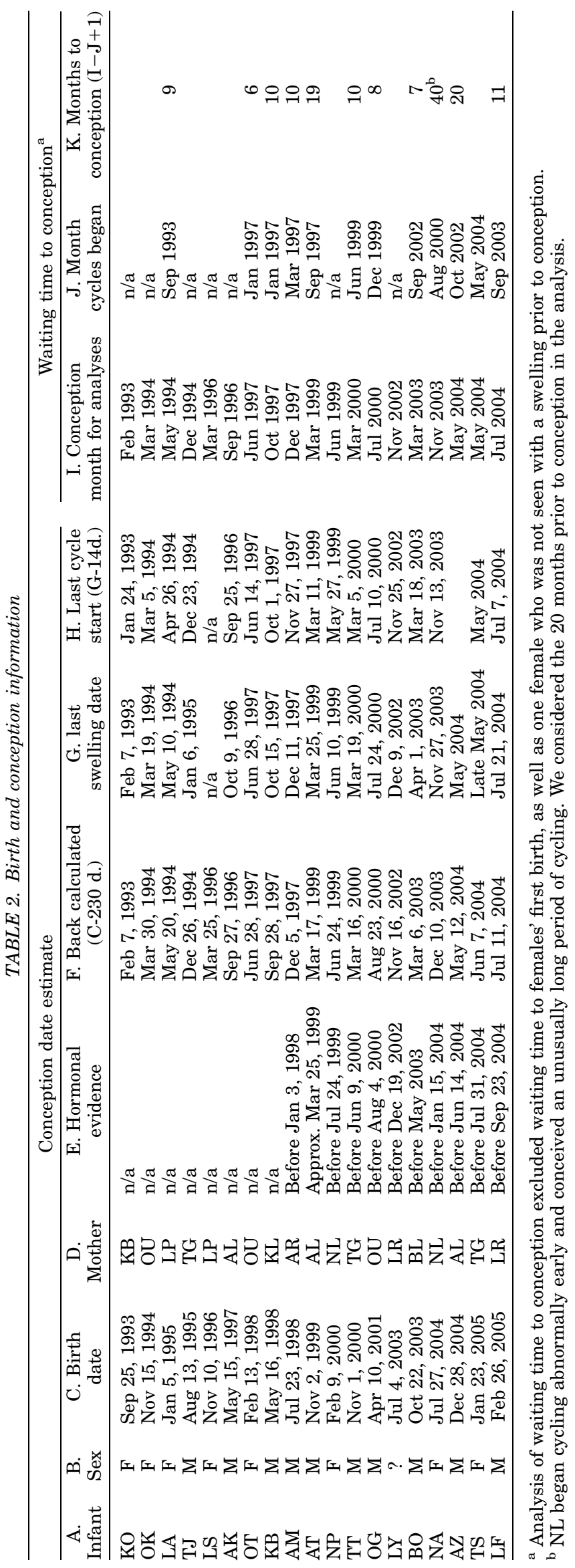


TABLE 3. Kanyawara chimpanzee diet January 1993-December 2004, including important food items listed by average feeding intensity

\begin{tabular}{|c|c|c|c|c|c|}
\hline Species (family) & $\begin{array}{l}\text { Months } \\
\text { consumed }\end{array}$ & $\begin{array}{c}\text { Average } \\
\text { consumption } \\
\text { across all months }{ }^{\mathrm{a}}\end{array}$ & $\begin{array}{c}\text { Average } \\
\text { feeding } \\
\text { intensity }\end{array}$ & $\begin{array}{l}\text { Maximum } \\
\text { feeding } \\
\text { intensity }\end{array}$ & $\begin{array}{c}\text { Caloric } \\
\text { content } \\
(\mathrm{kCal} / \mathrm{g})^{\mathrm{c}}\end{array}$ \\
\hline Mimusops bagshawei (Sapotaceae) & 51 & 12.4 & 31.2 & 83.1 & $2.26-2.93$ \\
\hline Uvariopsis congensis (Annonaceae) & 31 & 5.9 & 24.2 & 81.0 & $1.87-2.60$ \\
\hline Linociera johnstonii (Oleaceae) & 9 & 1.6 & 23.4 & 66.6 & $2.07-2.84$ \\
\hline Pseudospondias microcarpa (Anacardiaceae) & 17 & 2.9 & 21.6 & 57.1 & $1.60-2.54$ \\
\hline Ficus natalensis (Moraceae) & 86 & 13.6 & 20.3 & 68.9 & $1.34-2.36$ \\
\hline Teclea nobilis (Rutaceae) & 8 & 1.1 & 17.2 & 48.1 & $\mathrm{n} / \mathrm{a}$ \\
\hline Ficus sansibarica (Moraceae) & 100 & 11.5 & 14.7 & 76.4 & $2.46-3.05$ \\
\hline Ficus saussureana (Moraceae) & 42 & 3.5 & 10.6 & 51.2 & $1.73-2.60$ \\
\hline Ficus exasperata (Moraceae) & 86 & 6.4 & 9.5 & 84.8 & $2.26-2.90$ \\
\hline All Ripe Fruits & 128 & 68.1 & 68.1 & 96.1 & \\
\hline All Ripe Drupe & 120 & 30.9 & 32.9 & 84.9 & \\
\hline \multicolumn{6}{|l|}{ (Non-fig) Fruits } \\
\hline All Ripe Figs & 128 & 37.2 & 37.2 & 90.6 & \\
\hline Leaves & 126 & 8.0 & 8.1 & 40.7 & \\
\hline Piths & 128 & 20.1 & 20.1 & 59.0 & \\
\hline Other (flowers, meat, etc.) & 111 & 3.8 & 4.4 & 58.3 & \\
\hline
\end{tabular}

a $\%$ of chimpanzee monthly diet, months with at least 50 observation hours.

b Average \% of diet for months in which the item was consumed at all.

c Metabolizable energy per gram dry weight from nutritional analyses at Kanyawara (Conklin-Brittain et al., 2006), range reflects minimum to maximum estimates of available energy with varying estimates of fiber fermentation. Nutritional information for Teclea nobills unavailable. Note that caloric content does not incorporate important factors for dietary quality, such as intake rate, cost of processing, cost of travel, specific nutrient content, and patch size.

available across seasons. As previously reported at Kanyawara (Wrangham et al., 1996), there was a negative correlation between drupe consumption and fig consumption $\left(r_{\mathrm{s}}=-0.770, N=128, P_{2}<0.001\right)$. Thus there was consistent evidence that Kanyawara chimpanzees use figs as intermediate fallback foods when the more-seasonal drupes are not plentiful. Low-quality fallback foods-leaves and piths, particularly of terrestrial herbaceous vegetation-comprised $29 \%$ of the diet on average.

Drupe consumption was a significant predictor of monthly fruit consumption but accounted for only $13 \%$ of the total variation in fruit consumption $\left(R^{2}=0.132, \mathrm{df}=\right.$ $127, P<0.001)$. Therefore, to avoid problems of colinearity, we analyzed total fruit consumption and drupe fruit consumption separately in our reproductive analyses, with the recognition that these variables were neither independent nor so tightly correlated so as to be redundant.

\section{Sexual swellings}

Nonpregnant females with sexual swellings were observed in 101/128 (79\%) of study months, with a maximum of six fully swollen females in a single month (during a fruiting season of $M$. bagshawei). We compared the percentage of potentially-reproductive females exhibiting sexual swellings during months in which a single fruit species (from Table 2) comprised $>40 \%$ of the female chimpanzee diet ("seasons"). A larger proportion of females exhibited maximal sexual swellings during seasons of the major drupe fruits than during seasons for the prominent fig species (Mann-Whitney $U: z=-2.669$, $\left.N_{\mathrm{DR}}=36, N_{\mathrm{FIG}}=34, P_{2}=0.008\right)$ or during other months when no fruit species predominated $\left(z=-2.973, N_{\mathrm{DR}}=\right.$ $36, N_{\mathrm{NONE}}=58, P_{2}=0.003$, Fig. 1 ). There was no significant difference in sexual swelling frequency between the major fig seasons and months that did not comprise a fruit season $\left(z=-0.318, N_{\mathrm{FIG}}=34, N_{\mathrm{NONE}}=58, P_{2}=\right.$ 0.75). The proportion of females with sexual swellings in

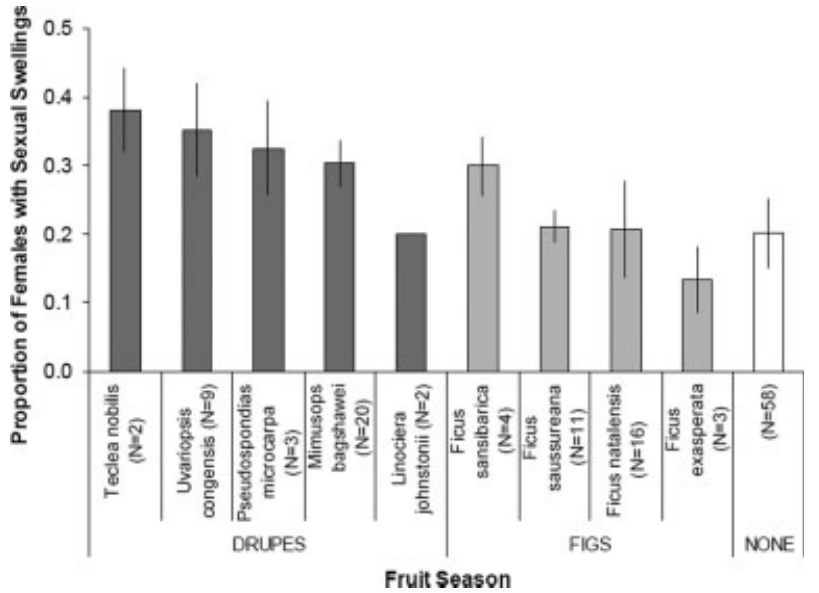

Fig. 1. Proportion of potentially-reproductive females with sexual swellings during different fruiting seasons (i.e., $\geq 40 \%$ of diet consisted of fruit species indicated). Mean $\pm \mathrm{SE}$.

a given month was not significantly correlated with the percentage of all fruit in the $\operatorname{diet}\left(r_{\mathrm{s}}=0.036, N=128, P_{2}\right.$ $=0.68)$, but was positively and significantly correlated with the consumption of drupe fruit $\left(r_{\mathrm{s}}=0.186, N=128\right.$, $\left.P_{2}=0.04\right)$. Consistent with the dietary finding of an inverse correlation between drupe and fig consumption, the strongest correlate of sexual swelling frequency was the difference in consumption rates of drupe and fig fruits in a given month $\left(r_{\mathrm{s}}=0.230, N=128, P_{2}=0.009\right)$.

\section{Ovarian hormones}

Monthly urinary $\mathrm{E}_{1} \mathrm{C}$ and $\mathrm{PdG}$ averages were correlated with one another in both noncycling $(r=0.539$, $\left.N=68, P_{2}<0.001\right)$ and cycling-baseline reproductive states $\left(r=0.374, N=37, P_{2}=0.01\right)$. Baseline $\mathrm{E}_{1} \mathrm{C}$ and 


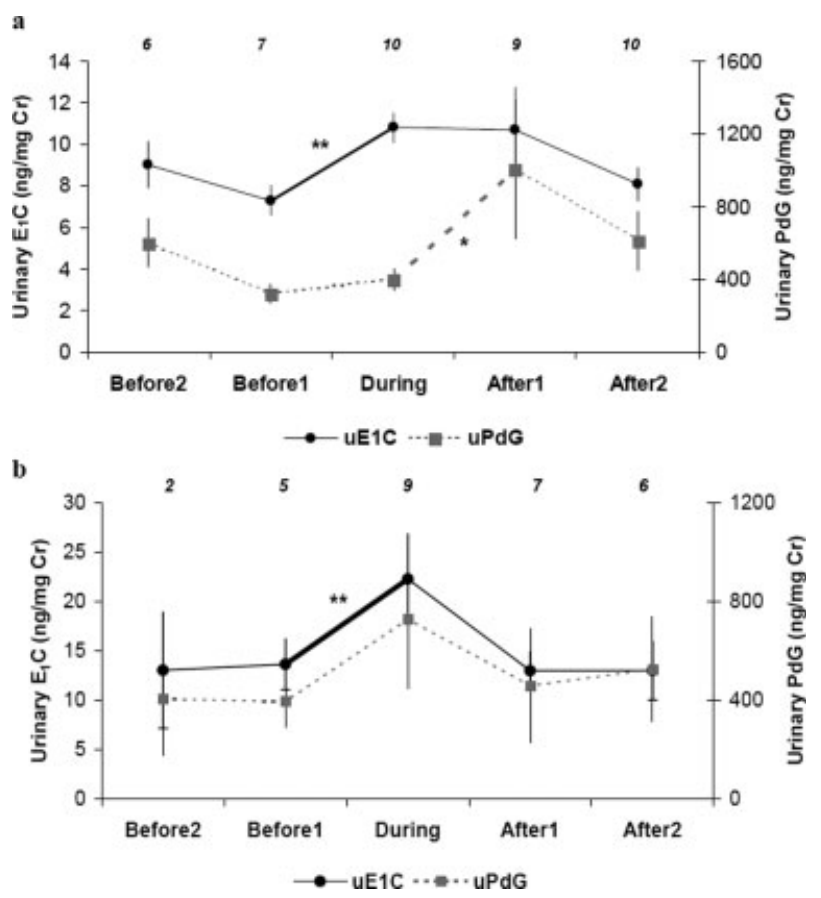

Fig. 2. Ovarian hormone levels before, during and after drupe fruit seasons: (a) non-cycling and (b) cycling baseline. Plots illustrate mean \pm standard error, with $N=$ number of seasons or control months with hormonal data available. Before1/After1 = month immediately preceding or following fruiting season; Before2/After2 = month preceding Before1 or following After1; During $=\operatorname{month}(\mathrm{s})$ of fruiting season; $* P<0.05,{ }^{* *} P<0.01$.

PdG levels of cycling females were significantly correlated with levels of non-cycling females $\left(\mathrm{E}_{1} \mathrm{C}: r=0.275\right.$, $N=39, P=0.05$; PdG: $\left.r=0.417, N=36, P_{2}=0.006\right)$. Cycling-peak $\mathrm{E}_{1} \mathrm{C}$ levels, however, were unrelated to baseline or non-cycling $\mathrm{E}_{1} \mathrm{C}$ levels (peak vs. baseline: $r=$ 0.153, $N=20, P_{2}=0.26$; peak vs noncycling: $r=$ $\left.-0.127, N=34, P_{2}=0.24\right)$.

Sexual swelling frequencies increased during particular drupe fruit seasons, suggesting that ovarian function might also increase at these times. We identified 10 seasons between Dec 1997 and Dec 2003 (our period of endocrine sampling) during which a particular drupe fruit comprised more than $40 \%$ of the diet for one month or more (mean 1.9 months): 5 seasons of $M$. bagshawei, 3 seasons of $U$. congensis, and 1 season each of P. microcarpa and Teclea nobilis. Compared with the preceding month, drupe seasons were characterized by significantly higher $\mathrm{E}_{1} \mathrm{C}$ levels in both noncycling (Fig. 2a: $t_{\text {pair }}=-3.633$, df $=7, P_{2}=0.008$ ) and cycling-baseline samples (Fig. $2 \mathrm{~b}: t_{\text {pair }}=-8.706, \mathrm{df}=$ $\left.3, P_{2}=0.003\right)$. Cycling-baseline PdG levels increased nonsignificantly $\left(t_{\text {pair }}=-1.105, \mathrm{df}=6, P_{2}=0.69\right)$, and $\mathrm{PdG}$ levels of non-cycling females increased significantly following the fruit season $\left(t_{\text {pair }}=-2.361, \mathrm{df}=8, P_{2}=0.05\right)$, a time when $\mathrm{E}_{1} \mathrm{C}$ levels remained elevated. We could not statistically examine the effect on cycling-peak $\mathrm{E}_{1} \mathrm{C}$ levels because estrous females were typically not adequately represented in control months. Consistent with results in the previous section, the proportion of reproductive females with sexual swellings increased significantly during the drupe fruit seasons $\left(t_{\text {pair }}=-2.429, \mathrm{df}=9, P_{2}=0.02\right)$, then decreased significantly following the season $\left(t_{\text {pair }}=\right.$ $-2.371, \mathrm{df}=9, P_{2}=0.02$ ).
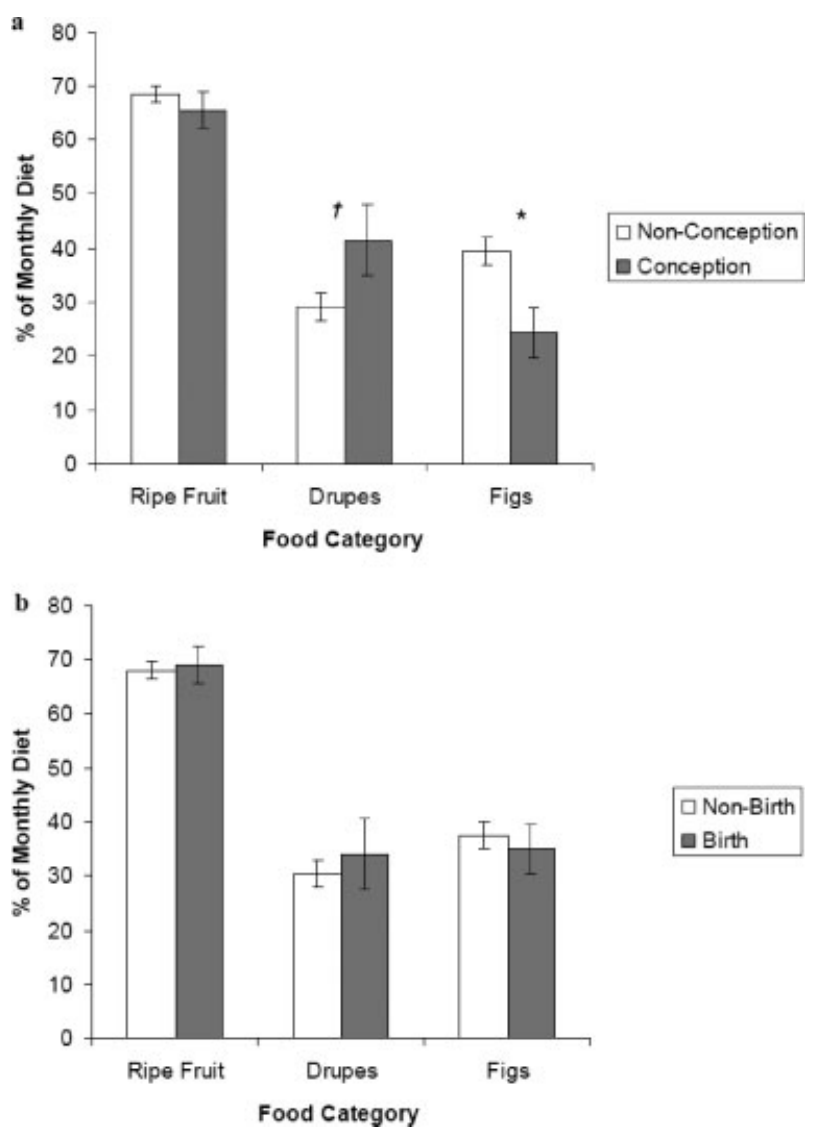

Fig. 3. Percentage of drupe fruit, fig fruit, and all ripe fruit in the chimpanzee diet (mean $\pm \mathrm{SE}$ ) during (a) conception versus nonconception months (b) birth versus non-birth months. Mean $\pm \mathrm{SE},{ }^{*} P<0.05,{ }^{\dagger} P<0.10$.

\section{Conception and birth}

Fruit consumption was not significantly different between conception and nonconception months (MannWhitney $U, z=-1.028, N_{\mathrm{C}}=18, N_{\mathrm{NC}}=110, P_{2}=$ $0.30)$. However, chimpanzees were more likely to be consuming drupe than fig fruits when they conceived. The increase in drupe fruit consumption during conception versus nonconception months approached significance (Fig. 3a; $z=-1.786, N_{\mathrm{C}}=18, N_{\mathrm{NC}}=110, P_{2}=0.07$ ), while the fig composition of the diet was significantly lower in conception months $\left(z=-2.231, N_{\mathrm{C}}=18, N_{\mathrm{NC}}\right.$ $\left.=110, P_{2}=0.03\right)$. Thus, the magnitude of the difference between drupe and fruit composition of the diet was relatively greater during months that produced conceptions $\left(z=-2.173, N_{\mathrm{C}}=18, N_{\mathrm{NC}}=110, P_{2}=0.03\right)$. By contrast, birth months did not differ statistically for fruit consumption (Fig. $3 \mathrm{~b} ; z=-0.389, N_{\mathrm{B}}=15, N_{\mathrm{NB}}=113$, $\left.P_{2}=0.70\right)$, nor for drupe $\left(z=-0.633, N_{\mathrm{B}}=15, N_{\mathrm{NB}}=\right.$ $\left.113, P_{2}=0.53\right)$ or fig consumption $\left(z=-0.315, N_{\mathrm{B}}=\right.$ $15, N_{\mathrm{NB}}=113, P_{2}=0.75$ ).

We next examined whether cumulative effects of diet could predict the speed of conception. Indeed, for 12 conceptions to parous females for which we could identify both the first month of cycling and the month of conception, waiting time to conception was significantly predicted by the mean percentage of fruit in the diet over that period $\left(R^{2}=0.569\right.$, df $=11, P=0.005$, Fig. 4a). Because three females contributed two data points to 

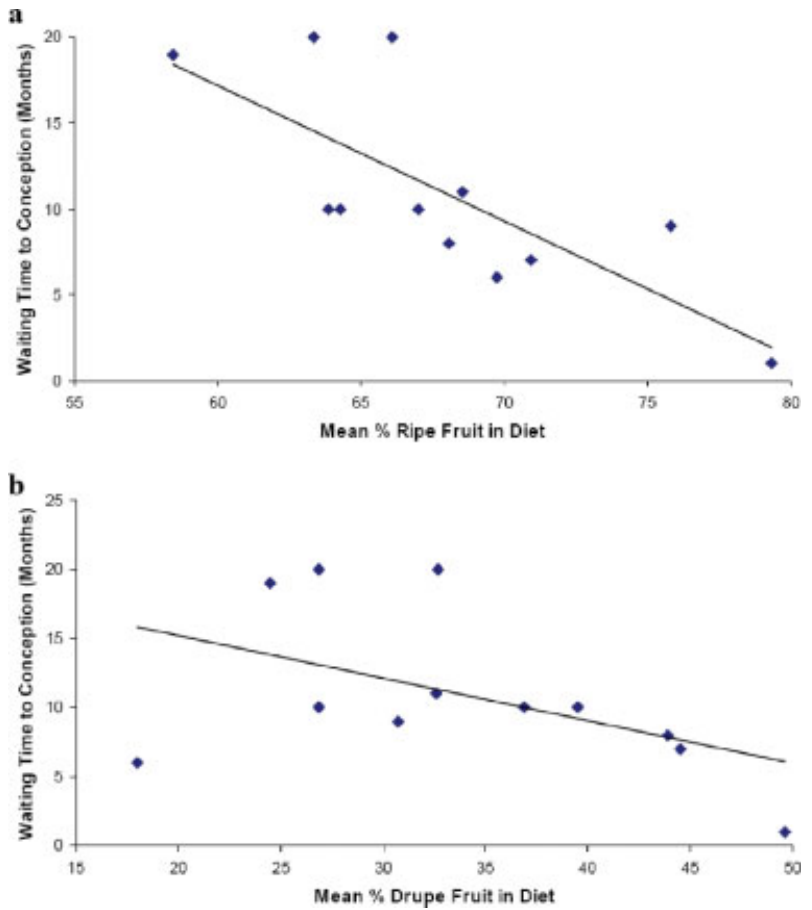

Fig. 4. Waiting time from resumption of estrous cycles to conception as a factor of (a) the mean percentage of ripe fruit consumed during the waiting period, and (b) the mean percentage of drupe fruit consumed during the waiting period. [Color figure can be viewed in the online issue, which is available at www.interscience.wiley.com.]

this sample, we also conducted a partial correlation to control for individual effects on the waiting time to conception. The correlation remained significant (partial $r=$ -0.683 , df $=9, P=0.02$ ).

Waiting time to conception was not significantly predicted by the mean percentage of drupe fruit in the diet $\left(R^{2}=0.232, \mathrm{df}=11, P=0.11\right.$, Fig. $\left.4 \mathrm{~b}\right)$. However, we noted that one female conceived over a period of the lowest average consumption, yet had conceived at the end of a season of the key drupe fruit $M$. bagshawei. Excluding this one datum, there was a very strong significant relationship between average drupe fruit consumption and reduced waiting time to conception $\left(R^{2}=0.598, \mathrm{df}=10, P=0.005\right)$.

\section{DISCUSSION}

Studies of reproduction in human females emphasize the importance of energy intake and expenditure for modulating ovarian hormone production and the immediate probability of conception (Bullen et al., 1985; Ellison and Lager, 1986; Ellison, et al., 1989, 1993; PanterBrick et al., 1993; Jasienska and Ellison, 1998). Rather than portraying such response as dysfunctional, reproductive ecologists have described a model whereby reproductive function varies along a continuum with energetic condition so that reproductive effort is not wasted during conditions unfavorable to producing and raising offspring (Ellison, 1990, 2001, 2003). While animal models typically find that severe energy shortage is related to reproductive suppression (Wasser and Barash, 1993; Schneider and Wade, 2000), few data are available to evaluate the reproductive consequences of the more moderate variation in energy availability typically experi- enced by wild primates. Studies of primate seasonality do, however, suggest that many primates take the opposite strategy of humans: births, rather than conceptions, tend to coincide with times of highest food availability (Lindburg, 1987; Ganzhorn et al., 2003).

Our study, investigating reproductive variation in relation to natural fluctuations in feeding ecology, supports the hypothesis that chimpanzees share a similar pattern to humans. In the Kanyawara chimpanzees, female reproductive capacity was consistently linked to dietary quality as measured by the proportion of feeding time spent eating ripe fruits, particularly drupes. Specifically, peaks in fruit utilization by the chimpanzee community predicted the number of sexually receptive females, estrogen levels (in both cycling-baseline and noncycling females), conception timing, and the waiting time to conception. These data are the first to show that increased access to preferred foods leads to improved ovarian performance and/or enhanced conception probability in chimpanzees.

Unfortunately, the nature of chimpanzee social organization and weak female sociality preclude the collection of fine-grained and consistent data on individual female's feeding behavior over long-term study periods, particularly as forest visibility conditions often inhibit our ability to simultaneously sample all individuals in a party. Therefore, one limitation of our study is that we must infer dietary quality from data collected on whole chimpanzee parties, when in fact it is likely that individual females within the community vary in their energy intake. Pusey et al. (2005), for example, demonstrated that high-ranking female chimpanzees at Gombe outweighed low-ranking females and had greater stability in body weight across seasons. Similarly, in comparison with the central group of females we examined in this article, a second cluster of females at Kanyawara (the northern neighborhood) have lower access to preferred food resources (Skorupa 1988; Emery Thompson et al., 2007), are lower-ranking (Kahlenberg et al., in review), have lower ovarian hormone levels (Emery Thompson et al., 2006, 2007), and have lower birth rates and offspring survivorship (Emery Thompson et al., 2007). While this contrast clearly demonstrates individual variability in reproductive function, by excluding the northern females from our analysis we hope to have minimized the impact of such variation on our results.

Another limitation is that our analysis focuses on variables that estimate energy intake, while we have not been able to measure energy expenditure. In human females, high energy expenditure has a significant influence on reproductive function independent of net weight gained or lost (Bullen et al., 1985; Jasienka and Ellison, 1998). Given that chimpanzee foods have variable distribution patterns throughout the forest and that individuals vary in their tolerance for scramble competition (Wrangham, 2000), and with the added complication that increased food availability leads to energeticallycostly behaviors such as hunting, copulation and associated male competition for mates (Matsumoto-Oda, 1999; Emery Thompson and Wrangham, 2006; Gilby and Wrangham, 2007), we expect that there is a complex relationship between energy intake and energy expenditure in chimpanzees.

Despite these limitations, we find several reasons to be confident that our data adequately address the hypothesis that dietary quality influences female reproductive function. First, we applied a multilayered approach to examine the influence of dietary fluctuations on repro- 
ductive function, including both proximate mechanisms (ovarian hormones) and reproductive outcomes (conception success). Second, the central group of females we examined have widely overlapping core areas, representing access to the same resource areas (Emery Thompson and Wrangham, 2007); aggression among female residents at Kanyawara is also exceedingly low $(<0.005$ aggressive acts/hour, Kahlenberg et al., in review), reducing the concern that direct feeding competition would lead to strong disparities in resource access. Third, given the chimpanzees' fission-fusion strategy, an entire party is typically contained within a single food patch, meaning that all individuals are consuming the same item (though perhaps at different rates). Chimpanzees in the same party consumed different food items in less than $1 \%$ of our observations. Fourth, party-wide feeding observations have been shown to provide an accurate reflection of individual dietary composition in chimpanzees at Budongo and Gombe (Emery Thompson, 2005a). Fifth, fruiting seasons of preferred drupes were typically abrupt and brief, reflecting both qualitative and quantitative shifts in the chimpanzee diet; while individuals surely vary in rate at which they consume the best foods, the onset of a major fruiting season should positively influence the energy intake of all individuals studied.

The evidence that female chimpanzees are reproductively sensitive to fluctuation in food supply has implications for understanding chimpanzee behavioral ecology. Greater food availability can be expected to promote more sexual swellings, a shorter interbirth interval, and hence a higher frequency of sexual behavior, all of which influence behavior. For example the presence of sexual swellings is a significant predictor of female attractiveness, influencing copulation rates, association rates with males, and aggression received from males (Deschner et al., 2004; Emery Thompson, 2005b; Muller et al., 2006; Emery Thompson and Wrangham, in review). Accordingly, behavioral comparisons will benefit from comparative measures of food availability.

Second, our data provide evidence of striking similarities between chimpanzee and human reproductive ecology. In human females, reproductive function, including ovarian hormone production, timing of conception, and duration of lactation amenorrhea, is closely tied to energetic condition (Ellison et al., 1993; Ellison, 2001, 2003; Valeggia and Ellison, 2001). Increases in dietary quality appear to have had two kinds of effect on chimpanzees at Kanyawara. First, they had threshold effects on female reproductive state, i.e., the onset of cycling after lactational amenorrhea, and the display of sexual swelling after a period of quiescence. These changes are easily observed and reflect broad shifts in ovarian function (Emery Thompson, 2005b). While studies have linked cycling in chimpanzees with environmental variability by correlating reproductive activity with rainfall patterns (Wallis, 2002; Anderson et al., 2006), our data suggest that the avenue by which greater climatic factors such as rainfall influence reproductive function are via effects on the chimpanzees' food supply.

Additionally, dietary quality had tonic effects on estrogen levels even without any (externally visible) change in reproductive state. Both noncycling and cycling nonswollen females exhibited increased estrogen levels during fruiting seasons. In swollen females, we were unable to determine if estrogen levels were predicted by diet because there were few females with sexual swellings in periods of poor dietary quality. Given the rapid changes in estrogen that occur during the maximal swelling period in chimpanzees (Deschner et al., 2003, 2004; Emery and Whitten, 2003; Emery Thompson, 2005b) and the irregular nature of sampling success in the field, it is a challenge to adequately sample the maximally swollen condition well enough to examine monthly values. The influence of preswelling estrogen values, equivalent to our "baseline" category, on conception has not been expressly examined in chimpanzees, though in humans mid-follicular estrogen has been found to be more strongly correlated with conception success than late follicular estrogen levels (Lipson and Ellison, 1996). This is perhaps because estrogen production potentiates and correlates with growth of the ovarian follicle (Wood, 1994), which significantly impacts subsequent gamete and embryo development (Mermillod et al., 1999; Nogueira et al., 2006).

Energy availability is critical to female reproductive success, particularly among primates for which reproductive costs are high (Schneider and Wade, 2000; Knott, 2001). Thus, a variety of studies of primates have demonstrated a positive effect of resource availability or maternal condition on birth rates (e.g., Papio cynocephalus: Bercovitch, 1987; Macaca fuscata, Suzuki et al., 1998; Propithecus verreauxi: Richard et al. 2000). Beyond this, however, our data suggest that humans and chimpanzees share the following set of reproductive traits: (1) responsiveness to current rather than future energetic conditions; (2) repeated cycling before conception; and (3) a continuous scale of ovarian response, as opposed to reproductive suppression that affects reproduction in an all or nothing manner. For such slowreproducing species experiencing an uncertain food supply, selection favors an adaptable timing of conception rather than a predictable birth season. The relationship in chimpanzees between mean dietary quality and waiting time to conception suggests that there is a cumulative effect of dietary quality on reproductive capacity; this is consistent with the hypothesis that successful reproduction is dependent on the storage of suitable energy reserves to buffer a reproductive effort through successive seasons.

A number of primate species, including some Old World monkeys, clearly do not fit this mold, conceiving during very restricted seasons or on their first cycle, or timing conception in anticipation of a predictable future period of abundance (Lindburg, 1987; Ganzhorn et al., 2003). However, a few other primate species have been found to meet conditions (1) and (2) described above. Orangutans (Pongo pygmaeus) at Gunung Palung National Park in Borneo conceive during periods of high energy balance and resource availability, and ovarian hormone production is highest at these times (Knott, 1999). Sumatran long-tailed macaques (Macaca fascicularis) cycle and conceive more frequently during the times of greatest fruit abundance (van Schaik and van Noordwijk 1985, 1999). While many other primates maintain a seasonal response to external cues (e.g., day length) in captivity, long-tailed macaques breed throughout the year in captivity, suggesting that consistent energy intake changes their reproductive function (Smith, 1984). In muriquis (Brachyteles arachnoides), the distribution of copulations and births, and a lack of interannual consistency in mating season onset, suggests that female condition may be a proximate cue for reproduction (Strier et al., 2001; Strier and Ziegler, 2004). Promising preliminary evidence indicates that females 
may experience cycle-to-cycle changes in ovarian function as conception approaches (Strier and Ziegler, 2005). In baboons (Papio cynocephalus), reproductive parameters vary among wild-foraging populations, and groups shifting to resource-rich ranges experience dramatic improvements in reproductive rates, such as a 6-month reduction in birth interval (Altmann and Alberts 2003a, $2003 \mathrm{~b})$. Both onset of cycling and waiting time to conception have been tied to resource availability and/or maternal body weight in baboons (Bercovitch, 1987; Bercovitch and Strum, 1993), and variability in ovarian function under laboratory conditions has been linked with conception success in this species (Wasser, 1996).

These studies provide promising evidence to suggest that, rather than being a trait linked to unique aspects of costly reproductive investment in hominoids, a reproductive sensitivity to current energetic conditions may be linked to ecological circumstances in a number of primate species. Where habitats provide similar constraints on the availability and predictability of resources, and where fluctuations in energy availability occur on a more continuous scale (as opposed to boom-and-bust), we should expect flexible reproductive adaptations with enhanced sensitivity to available energy (van Schaik and van Noordwijk, 1985). Further study of apes and these other species is needed to evaluate the extent of variation in ovarian function among females and the degree of sensitivity to varying levels of environmental distress. Study of hormonal activity in these species could help elucidate whether females experience changes in ovarian function only at a certain energy threshold or in a doseresponse relationship with a range of ecological conditions. Finally, given an increased understanding of the diversity of female reproductive adaptations, variation in female conception strategy may be associated with other correlated social and physiological traits, such as dietary diversity and an enhanced ability to store energy.

\section{ACKNOWLEDGMENTS}

Local research support and permissions were obtained from the Uganda National Council for Science and Technology, the Uganda Wildlife Authority, and the Makerere University Biological Field Station. Daily data collection was done by Francis Mugurusi, the late Christopher Muruuli, Peter Tuhairwe, the late John Barwogeza, Christopher Katongole, and the late Donor Muhangyi, with field management by Michael Wilson, Martin Muller, Katherine Pieta, Carole Hooven, and Kimberly Duffy. The authors thank Peter Ellison, Cheryl Knott, Susan Lipson, Mark Leighton, Martin Muller, and three anonymous reviewers for suggestions on the presentation of these results.

\section{LITERATURE CITED}

Altmann J, Alberts SC. 2003a. Intraspecific variability in fertility and offspring survival in a non-human primate: behavioral control of ecological and social sources. In: Wachter K, editor. Offspring: human fertility behavior in a biodemographic perspective. Washington, DC: National Academy Press. p 140-169.

Altmann J, Alberts SC. 2003b. Variability in reproductive success viewed from a life-history perspective in baboons. Am J Hum Biol 15:401-409.

Anderson DP, Nordheim EV, Boesch C. 2006. Environmental factors influencing the seasonality of estrus in chimpanzees. Primates 47:43-50.
Balcomb SR, Chapman CA, Wrangham RW. 2000. Relationship between chimpanzee (Pan troglodytes) density and large, fleshy-fruit density: conservation implications. Am J Primatol 51:197-203.

Bercovitch FB. 1987. Female weight and reproductive condition in a population of olive baboons (Papio anubis). Am J Primatol 12:189-195.

Bercovitch FB, Strum SC. 1993. Dominance rank, resource availability, and reproductive maturation in female savanna baboons. Behav Ecol Sociobiol 33:313-318.

Boesch C, Boesch-Achermann H. 2000. The chimpanzees of the Taï forest: behavioural ecology and evolution. Oxford: Oxford University Press. 316 p.

Boyd I. 2000. State-dependent fertility in pinnipeds: contrasting capital and income breeders. Funct Ecol 14:623-630.

Brewer-Marsden S, Marsden D, Emery Thompson M. 2006. Demographic and female life history parameters of free-ranging chimpanzees at the chimpanzee rehabilitation project, River Gambia National Park. Int J Primatol 27:391-410.

Bullen BA, Skrinar GS, Beitins IZ, von Mering G, Turnbull BA, McArthur JW. 1985. Induction of menstrual disorders by strenuous exercise in untrained women. NEJM 312:13491353.

Chapman CA, White FJ, Wrangham RW. 1994. Party size in chimpanzees and bonobos: a reevaluation of theory based on two similarly forested sites. In: Wrangham RW, McGrew WC, de Waal FBM, Heltne PG, editors. Chimpanzee cultures. Cambridge: Harvard University Press. p 41-58.

Chapman CA, Wrangham RW. 1993. Range use of the forest chimpanzees of Kibale: implications for the understanding of chimpanzee social organization. Am J Primatol 31:263-273.

Conklin-Brittain NL, Knott CD, Wrangham RW. 2006. Energy intake by wild chimpanzees and orangutans: methodological considerations and a preliminary comparison. In: Hohman G, Robbins MM, Boesch C, editors. Feeding ecology in apes and other primates. Cambridge: Cambridge University Press. p 445-471.

Conklin-Brittain NL, Wrangham RW, Hunt KD. 1998. Dietary response of chimpanzees and cercopit hecines to seasonal variation in fruit abundance. II. Macronutrients. Int J Primatol 19:949-970.

Czekala NM, Gallusser S, Meier JE, Lasley BL. 1986. The development and application of an enzyme immunoassay for urinary estrone conjugates. Zoo Biol 5:1-6.

Dahl JF, Nadler RD, Collins DC. 1991. Monitoring the ovarian cycles of Pan troglodytes and P. paniscus: a comparative approach. Am J Primatol 24:195-209.

Deschner T, Heistermann M, Hodges K, Boesch C. 2003. Timing and probability of ovulation in relation to sex skin swelling in wild West African chimpanzees, Pan troglodytes verus. Anim Behav 66:551-560.

Deschner T, Heistermann M, Hodges K, Boesch C. 2004. Female sexual swelling size, timing of ovulation, and male behavior in wild West African chimpanzees. Horm Behav 46:204-215.

Drent R, Daan S. 1980. The prudent parent: energetics adjustments in avian breeding. Ardea 68:225-252.

Ellison PT. 1990. Human ovarian function and reproductive ecology: new hypotheses. Am Anthropol 92:933-952.

Ellison PT. 2001. On fertile ground. Cambridge: Harvard University Press.

Ellison PT. 2003. Energetics and reproductive effort. Am J Hum Biol 15:342-351.

Ellison PT, Lager C. 1986. Moderate recreational running is associated with lowered salivary progesterone profiles in women. Am J Obstet Gynecol 154:1000-1003.

Ellison PT, Panter-Brick C, Lipson SF, O'Rourke MT. 1993. The ecological context of human ovarian function. Hum Reprod 8:2248-2258.

Ellison PT, Peacock NR, Lager C. 1989. Ecology and ovarian function among Lese women of the Ituri Forest, Zaire. Am J Phys Anthropol 78:519-526.

Emery MA, Whitten PL. 2003. Size of sexual swellings reflects ovarian function in chimpanzees (Pan troglodytes). Behav Ecol Sociobiol 54:340-351. 
Emery Thompson M. 2005a. Endocrinology and ecology of wild female chimpanzee reproduction. Ph.D. dissertation. Cambridge: Harvard University.

Emery Thompson M. 2005b. Reproductive endocrinology of wild female chimpanzees (Pan troglodytes schweinfurthii): methodological considerations and the role of hormones in sex and conception. Am J Primatol 67:137-158.

Emery Thompson M, Kahlenberg SM, Gilby IC, Wrangham RW. 2007. Core area quality is associated with variance in reproductive success among female chimpanzees at Kanyawara, Kibale National Park. Anim Behav 73:501-512.

Emery Thompson M, Wrangham RW. 2006. Comparison of sex differences in gregariousness in fission-fusion species: reducing bias by standardizing for party size. In: Newton-Fisher NE, Notman H, Reynolds V, Paterson J, editors. Primates of western Uganda. New York: Springer. p 209-226.

Emery Thompson M, Wrangham RW. Male mating interest varies with female fecundity in chimpanzees of Kanyawara, Kibale National Park (in review).

Emery Thompson M, Wrangham RW, Reynolds V. 2006. Urinary estrone conjugates and reproductive parameters in Kibale (Kanyawara) and Budongo (Sonso) chimpanzees. In: NewtonFisher NE, Notman H, Reynolds V, Paterson J, editors. Primates of western Uganda. New York: Springer. p 227-246.

Furuichi T, Hashimoto C, Tashiro Y. 2001. Fruit availability and habitat use by chimpanzees in the Kalinzu Forest, Uganda: examination of fallback foods. Int J Primatol 22:929-945.

Gadgil M, Bossert WH. 1970. Life historical consequences of natural selection. Am Nat 104:1-24.

Ganzhorn JU, Klaus S, Ortmann S, Schmid J. 2003. Adaptations to seasonality: some primate and nonprimate examples. In: Kappeler PM, Pereira ME, editors. Primate life histories and socioecology. Chicago: University of Chicago Press. p 132-144.

Gilby IC, and Wrangham RW. 2007. Risk-prone hunting by chimpanzees (Pan troglodytes schweinfurthii) increases during periods of high diet quality. Behav Ecol Sociobiol 61:17711779.

Goodall J. 1986. The chimpanzees of gombe: patterns of behavior. Cambridge: Belknap Press. p. 673

Graham CE, Warner H, Misener J, Collins DC, Preedy JRK. 1977. The association between basal body temperature, sexual swelling and urinary gonadal hormone levels in the menstrual cycle of the chimpanzee. J Reprod Fertil 50:23-28.

Hladik CM. 1977. Chimpanzees of Gabon and chimpanzees of Gombe: some comparative data on the diet. In: Clutton-Brock $\mathrm{TH}$, editor. Primate ecology: studies of feeding and ranging behaviour in lemurs, monkeys and apes. New York: Academic Press. p 481-501.

Isabirye-Basuta G. 1989. Feeding ecology of chimpanzees in the Kibale Forest, Uganda. In: Heltne PG, Marquardt LA, editors. Understanding chimpanzees. Cambridge: Harvard University Press. p 116-127.

Jasienska G, Ellison PT. 1998. Physical work causes suppression of ovarian function in women. Proc Roy Sci London Ser B 265:1847-1851.

Kahlenberg SM, Emery Thompson M, Wrangham RW. Female competition over core areas among Kanyawara chimpanzees, Kibale National Park, Uganda (in review).

Kesner JS, Knecht EA, and Krieg EF Jr. 1995. Stability of urinary female reproductive hormones stored under various conditions. Reprod Toxicol 9:239-244.

Knott CD. 1997. Field collection and preservation of urine in orangutans and chimpanzees. Trop Biodivers 4:95-102.

Knott CD. 1999. Reproductive physiological and behavioral responses of orangutans in Borneo to fluctuations in food availability, Ph.D. dissertation. Cambridge, MA: Harvard University.

Knott CD. 2001. Ape models of female reproductive ecology. In: Ellison PT, editor. Reproductive ecology and human evolution. Chicago: Aldine. p 429-463.

Koenig A, Borries C, Chalise MK, Winkler P. 1997. Ecology, nutrition, and timing of reproductive events in an Asian primate, the Hanuman langur (Presbytis entellus). J Zool (London) 243:215-235.
Leighton M. 1993. Modeling diet selectivity by Bornean orangutans: evidence for integration of multiple criteria for fruit selection. Int J Primatol 14:257-313.

Lewis RJ, Kappeler PM. 2005. Are Kirindy sifaka capital or income breeders? It depends. Am J Primatol 67:365-369.

Lindburg DG. 1987. Seasonality of reproduction in primates. In: Mitchell G, Erwin JM, editors. Comparative primate biology, Vol. 2B: Behavior, cognition, and motivation. New York: Alan R. Liss. p 167-218.

Lipson SF, Ellison PT. 1996. Comparison of salivary steroid profiles in naturally occurring conception and non-conception cycles. Hum Reprod 11:2090-2096.

Marshall AJ, Wrangham RW. Evolutionary consequences of fallback foods. Int J Primatol 28 (in press).

Martin D, Graham CE, Gould KG. 1978. Successful artificial insemination in the chimpanzee. Symp Zool Soc Lond 43:249260.

Matsumoto-Oda A. 1999. Mahale chimpanzees: grouping patterns and cycling females. Am J Primatol 47:197-207.

McArthur JW, Beitins IZ, Gorman A, Collins DC, Preedy JRK, Graham CE. 1981. The interrelationship between sex skin swelling and the urinary excretion of $\mathrm{LH}$, estrone, and pregnanediol by the cycling female chimpanzee. Am J Primatol 1:265-270.

Mermillod P, Oussaid B, Cognie Y. 1999. Aspects of follicular and oocyte maturation that affect the developmental potential of embryos. J Reprod Fertil Suppl 54:449-460.

Mitani JC, Watts DP, Lwanga JS. 2002. Ecological and social correlates of chimpanzee party size and composition. In: Boesch C, Hohmann G, Marchant LF, editors. Behavioural diversity in chimpanzees and Bonobos. Cambridge: Cambridge University Press. p 102-111.

Muller MN, Emery Thompson M, Wrangham RW. 2006. Male chimpanzees prefer mating with old females. Curr Biol 16:2234-2238.

Newton-Fisher NE. 1999. The diet of chimpanzees in the Budongo Forest Reserve, Uganda. Afr J Ecol 37:355-365.

Nogueira D, Friedler S, Schachter M, Raziel A, Ron-El R, Smitz J. 2006. Oocyte maturity and preimplantation development in relation to follicle diameter in gonadotropin-releasing hormone agonist or antagonist treatments. Fertil Steril 85:579583.

Panter-Brick C, Lotstein DS, Ellison PT. 1993. Seasonality of reproductive function and weight loss in rural Nepali women. Hum Reprod 8:684-690.

Pusey AE, Oehlert GW, Williams J, Goodall J. 2005. Influence of ecological and social factors on body mass of wild chimpanzees. Int J Primatol 26:3-31.

Pusey AE, Williams J, Goodall J. 1997. The influence of dominance rank on the reproductive success of female chimpanzees. Science 277:828-831.

Richard AF, Dewar RE, Schwartz M, Ratsirarson J. 2000. Mass change, environmental variability and female fertility in wild Propithecus verreauxi. J Hum Evol 39:381-391.

Schneider JE, Wade GN. 2000. Inhibition of reproduction in service of energy balance. In: Wallen K, Schneider JE, editors. Reproduction in context: social and environmental influences on reproduction. Cambridge: MIT Press. p 35-82.

Sherry DS. 2002. Reproductive seasonality in chimpanzees and humans: ultimate and proximate factors, Ph.D. dissertation. Cambridge, MA: Harvard University.

Shideler SE, Munro CJ, Tell L, Owitt G, Laughlin LS, Chatterton R Jr, Lasley BL. 1990. The relationship of serum estradiol and progesterone concentrations to the enzume immunoassay measurements of urinary estrone conjugates and immunoreactive pregnanediol-3-glucuronide in Macaca mulatta. Am J Primatol 22:113-122.

Shimizu K, Douke C, Fujita S, Matsuzawa T, Tomonaga M, Tanaka M, Matsubayashi K, Hayashi M. 2003. Urinary steroids, FSH and CG measurements for monitoring the ovarian cycle and pregnancy in the chimpanzee. J Med Primatol 32:15-22.

Skorupa JP. 1988. The effects of selective timber harvesting on rain-forest primates in Kibale Forest, Uganda, Ph.D. dissertation. University of California, Davis. 519 p. 
Smith EO. 1984. Non-seasonal breeding patterns in stumptail macaques (Macaca arctoides). Primates 25:117-122.

Strier KB, Mendes SL, Santos RR. 2001. Timing of births in sympatric brown howler monkeys (Alouatta fusca clamitans) and Northern muriquis (Brachyteles arachnoides hypoxanthus). Am J Primatol 55:87-100.

Strier KB, Ziegler TE. 2004. How hormones help: deciphering the reproductive patterns of wild northern muriquis (Brachyteles hypoxanthus). Am J Primatol 62:119-130.

Strier KB, Ziegler TE. 2005. Variation in the resumption of cycling and conception by fecal androgen and estradiol levels in female northern muriquis (Brachyteles hypoxanthus). Am J Primatol 67:69-81.

Suzuki S, Noma N, Izawa K. 1998. Inter-annual variation of reproductive parameters and fruit availability in two populations of Japanese macaques. Primates 39:313-324.

Takasaki H, Hiraiwa-Hasegawa M, Takahata Y, Byrne RW, Kano T. 1986. A case of unusually early postpartum resumption of estrous cycling in a young female chimpanzee in the wild. Primates 27:517-519.

Taussky HH. 1954. A microcolorimetric determination of creatinine in urine by the Jaffe reaction. J Biol Chem 208:853-861.

Trivers RL. 1972. Parental investment and sexual selection. In: Campbell B, editor. Sexual selection and the descent of man 1871-1971. Chicago: Aldine. p 136-179.

Valeggia C, Ellison PT. 2001. Lactation, energetics, and postpartum fecundity. In: Ellison PT, editor. Reproductive ecology and human evolution. Chicago: Aldine de Gruyter.

van Noordwijk MA, van Schaik CP. 1999. The effects of dominance rank and group size on female lifetime reproductive success in wild long-tailed macaques, Macaca fascicularis. Primates 40(1):105-130.

van Schaik CP, van Noordwijk MA. 1985. Interannual variability in fruit abundance and the reproductive seasonality in Sumatran long-tailed macaques (Macaca fascicularis). J Zool (London) 206:533-549.

Wallis J. 1997. A survey of reproductive parameters in the freeranging chimpanzees of Gombe National Park. J Reprod Fertil 109:297-307.

Wallis J. 2002. Seasonal aspects of reproduction and sexual behavior in two chimpanzee populations: a comparison of Gombe (Tanzania) and Budongo (Uganda). In: Boesch C,
Hohmann G, Marchant LF, editors. Behavioural diversity in chimpanzees and bonobos. Cambridge: Cambridge University Press. p 181-191.

Wasser SK. 1996. Reproductive control in wild baboons measured by fecal steroids. Biol Reprod 55:393-399.

Wasser SK, Barash DP. 1983. Reproductive suppression among female mammals: implications for biomedicine and sexual selection theory. Q Rev Biol 58:513-538.

Wilson ML. 2001. Imbalances of power: how chimpanzees respond to the threat of intergroup aggression, Ph.D. dissertation. Cambridge, MA: Harvard University.

Wood JW. 1994. Dynamics of human reproduction: biology, biometry, demography. New York: Aldine de Gruyter.

Wrangham RW. 1977. Feeding behaviour of chimpanzees in Gombe National Park, Tanzania. In: Clutton-Brock TH, editor. Primate ecology: studies of feeding and ranging behaviour in lemurs, monkeys and apes. New York: Academic Press. p 503-537.

Wrangham RW. 2000. Why are male chimpanzees more gregarious than mothers? A scramble competition hypothesis. In: Kappeler PM, editor. Primate males: causes and consequences of variation in group composition. Cambridge: Cambridge University Press. p 248-258.

Wrangham RW, Chapman CA, Clark-Arcadi AP, Isabirye-Basuta G. 1996. Social ecology of Kanyawara chimpanzees: implications for understanding the costs of great ape groups. In: McGrew WC, Marchant LF, Nishida T, editors. Great ape societies. Cambridge: Cambridge University Press. p 45-57.

Wrangham RW, Conklin-Brittain NL, Hunt KD. 1998. Dietary response of chimpanzees and cercopithecines to seasonal variation in fruit abundance. I. Antifeedants. Int J Primatol 19:949-970.

Wrangham RW, Conklin NL, Chapman CA, Hunt KD. 1991. The significance of fibrous foods for Kibale forest chimpanzees. Philos T Roy Soc B334:171-178.

Yamagiwa J, Maruhashi T, Yumoto T, Mwanka N. 1996. Dietary and ranging overlap in sympatric gorillas and chimpanzees in Kahuzi-Biega National Park, Zaire. In: McGrew WC, Marchant LF, Nishida T, editors. Great ape societies, 7 ed. Cambridge: Cambridge University Press. p 82-98.

Yerkes RM. 1943. Chimpanzees: a laboratory colony. New Haven: Yale University Press. 